CUPAUAM 21, 1994, pp. 297-312

\title{
UN RIBAT INTERIOR EN LA MARCA MEDIA. EL CASO DE TQALABĪRA
}

\author{
SERGIO MARTINEZ LILLO \\ Dpto. Prehistoria y Arqueología, U.A.M.
}

\section{Resumen}

En el presente trabajo se plantea el estudio parcial de una típica ciudad de frontera en la Marca Media de al-Andalus durante el periodo omeya. Se analiza la función de madinat Talahĩra alahra como rihāt y por consiguiente el lugar donde los suenos musulmanes podían cumplir con el $\bar{y}$ ibād. Otro aspecto de interés es la ubicación de ciertos elementos de la ciudad como: alcazaba, acceso y puente; que proponemos pudo deberse a los conocimientos y experiencia del general muladí Amrūs.

\section{Summary}

In the present paper is outlined the partial study of a typical frontier city in the Middle Border of alAndalus during the Umayyad period. It is analyzed the function of madinat Talabira as a rihāt and therefore the place where the good muslims* could accomplish the $\bar{y}$ iba $\bar{d}$. Other interesting aspect is the location of several city's elements as: alcazaba, access and bridge; that we propose could be owing to the military architecture knowledge that had the general muladi 'Amrūs.

Uno de los motivos del presente trabajo es presentar un curioso empleo del agua para la protección y defensa pasiva de una típica ciudad de frontera, como fue el caso de la Talabīra islámica durante los siglos IX-XIII. Durante los tres primeros siglos (IX-XI), según nos comenta, entre otros autores, Ibn Gālib en su Farbat al-anfus fi ajbar al-Andalus (Vallvé, 1975, 378), Talabīra fue un bastión importante para el control y defensa del Tagr al-ausat contra las incursiones realizadas por los reyes cristianos. Siendo las más frecuentes las que llevaron a cabo los monarcas astur-leoneses, García I en el año 911 o 914 (Jiménez de Gregorio, 1983, 84), Ordoño II en los años 918 (Lèvi Provençal, 1950, 281) y 924 (Jiménez de Rada, 1968, 95) y Ramiro II en el año 958/959 (Jiménez de 
Rada, 1968, 102). Asimismo, como ya ha sido comentado con anterioridad por varios autores, la posesión de Talavera - junto con el de otros puntos de la zona toledana como Calatrava y Zorita de los Canes- proporcionaba a los monarcas omeyas de Córdoba el medio de controlar las diversas revueltas que se dieron en Toledo (González, 1975, 5758 y Manzano, 1989, 341-349).

En los siglos posteriores (XII-XIII) fue junto a otros enclaves de esta frontera como Trujillo, Toledo, Montánchez, etc., uno de los puntos que sufrió las diversas acometidas de las tropas almorávides y almohades durante las incursiones que llevaron a cabo por esta zona (Ibn Id̄āīi, 1951 y Huici, 1959 y 1961). Por ello, pensamos que es importante tener siempre presente el ambiente de inestabilidad militar y casi permanente estado de alarma en que debieron vivir las gentes de esta parte de la Marca Media. Sin embargo, antes de entrar en esos aspectos creemos interesante mencionar algo respecto al lugar donde se situó esta ciudad.

Al optar los ingenieros y arquitectos musulmanes por la ubicación que posteriormente dieron a esta ciudad dentro del modelo operativo ya definido por M. de Epalza (1985, 137-149), tuvieron muy en cuenta el factor del agua como sistema de defensa pasiva de toda la madinna. Por ello, y en el momento de su amurallamiento a mediados del siglo IX y posterior reforma del siglo x (año 936/937) ubicaron el perímetro de la ciudad de tal forma que quedase casi rodeado por completo de agua. En este sentido vemos que se siguen dinámicas de ocupación similares a los modelos operativos planteados también en puntos del Sharq al-Andalus, como son, entre otros, los casos de Xàtiva y Orihuela (Franco, 1991, 357-360).

Así pues, tenían el río Tajo como barrera por el sur, el cauce del arroyo de la Portiña al oeste y norte; por último el lecho de un segundo arroyo defendía la ciudad por su lado este y parte del noreste. Con ello el hábitat musulman, y muy probablemente también el anterior romano, conseguía tener un aspecto de península o isla, tal y como comenta Cornide en sus Viajes ... (Jiménez de Gregorio, 1983, 16). El nombre de este último cauce varía según los autores; el duque de Estrada habla del río Cochino, mencionando que discurre al este de la población y viene a desembocar al Tajo al pie de los muros" (Jiménez de Gregorio, 1983, 17). Sin embargo Jiménez de Gregorio en su obra ya señalada, hace referencia al arroyo Albaladiel como el cauce que rodea Talavera por oriente (1983, 65 y 75), por lo tanto es muy posible que estemos ante un cauce fluvial con dos denominaciones distintas.

Del aspecto que debió ofrecer esta villa fortificada en determinados momentos de su historia, como por ejemplo el asedio realizado por Alfonso VI, contamos con el comentario de Fray Andrés Torrejón (mediados del s. XVII). Por los datos que nos proporciona sabemos de las distintas obras defensivas y de la existencia de un foso que se llenaba con agua: " ... habian reparado sus murallas de torres muy juntas y bajas puertas, angostas y bien guardadas, ante el primero y segundo recinto babia una caba que se llenaba de agua" (Jiménez de Gregorio, 1983, 87). 
Esta breve descripción de la Talabīra taifa nos conduce de nuevo a uno de los motivos de este trabajo de investigación. En concreto nos referimos a la utilización, en esta ciudad toledana, de una presa que provocaba que el agua del río Tajo quedase retenida, llegando así la corriente al borde mismo de las murallas en el sector más meridional de esta fortaleza. En relación a este aspecto, cabe mencionar - a modo de hipótesis- que al estar los cauces de los dos arroyos secos o con poco caudal, durante la época estival, es posible que su lecho seco se llenase con el agua retenida por la presa. Así estaríamos ante una especie de embalse que mantendría un nivel homogéneo de agua en el anillo que rodeaba la fortificación talaverana. Con ello tendríamos una función más (medio defensivo) de este espacio plurifuncional urbano que es el agua y que deberíamos por lo tanto añadir a las ya propuestas de “... captación, transporte, almacenamiento, distribución y eliminación, .... (Epalza, 1991, 21-22).

Un aspecto que, hoy por hoy, es muy difícil saber, es si la misión de la presa era exclusivamente retener el agua hasta que ésta llegase al borde de la muralla sur, o por el contrario y como parece más lógico, tuviese también un importante papel agrícola (norias, captación para acequias, irrigación por inundación); utilidades que podrían alterarse ante la llegada de huestes enemigas. El uso de represas con el fin de obtener un volumen de agua considerable y funcionar como "repartidores", lo tenemos documentado en alguna población del levante peninsular como fue el caso de Orihuela, acertadamente estudiada por F. Franco (1988, 38 y 49). Asimismo, y como también debió ocurrir para el caso de la Talabīra omeya, las norias y cenias obtendrían de esta represa el agua necesaria para el recinto urbano (Franco, 1988, 38).

Esta óptima situación de la ciudad, pensamos se completaría con otra serie de medidas que aumentaban el valor del agua como complemento para la defensa de sus muros. Entre otras estaría el excavar y mejorar artificialmente el lecho seco de los arroyos mencionados.

Otra referencia ilustrativa del uso de esta presa con el fin ya comentado, la tenemos en las diversas versiones sobre la campaña que realizó el emir almorávide Alīb. Yūsuf en los años 1109/1110 por tierra de Toledo. La fecha varía según el autor de la crónica o el editor del texto:

- Ibn Idārī en su Bayān al-Mugrib, tomos que tratan sobre las dinastías norteafricanas, traducido por Huici Miranda (1959, 77-122 y Bosch, 1956, 184-185).

- Ibn al-Qattān en su Nazm al-ŷyumān (Ibn Id̄ārī, 1951, 151).

Según estas fuentes el día 13 de agosto del año 1109 (503 H.) el ejército almorávide con su emir al frente llegó y acampó delante de las murallas de Talavera, en esos momentos en manos cristianas desde su toma por Alfonso VI en 1085. Ese mismo día se lleva a cabo el primer asalto sin éxito por la imposibilidad de acercarse las tropas a la muralla debido al desmesurado nivel que tenía el río, gracias a la existencia de una presa -aguas abajo- que provocaba el estancamiento del agua al pie de los muros. A! día siguiente la presa fue destruida con lo que el nivel del río disminuyó hasta el punto de 
permitir el acceso franco a las murallas. El mismo día fue asaltada la cerca de la ciudad, refugiándose algunos de los defensores cristianos en el alcázar (antigua alcazaba). Por la noche, y ante el oscuro panorama que tendrían los refugiados al siguiente día deciden huir. Según al-Bayān al-mugrib los cristianos recluidos en ese bastión optan por descolgarse por los muros de la alcazaba logrando huir a través del campamento norteafricano (Huici, 1963, 122-123). Por el contrario el, Nazm al-ŷumān umn refiere que los sitiados, tras ponerse el litäm (típico velo utilizado por los guerreros almorávides), huyen a caballo perseguidos por los sitiadores (Ibn Id̄ārī, 1951, 102).

Por lo tanto, de los textos consultados se desprende que la zona de muralla protegida por el agua sería, por lo menos, toda la existente en el sector meridional, que corresponde a la actual Ronda del Cañillo, el flanco oriental (río Cochino o Albaladiel), y el occidental así como parte del septentrional (arroyo de la Portiña). Ya el geógrafo andalusí Ahmad al-Rāzī $(1953,82)$ pondera el sistema de fortificaciones que tenía Talavera, gracias al cual se defendia de los ataques enemigos.

M. Terrasse en su trabajo monográfico sobre Talavera de la Reina en la Edad Media, apuntaba ya la existencia de un foso a lo largo del perímetro de la fortificación medieval (Terrasse, 1970), foso que por el momento no hemos documentado en las distintas campañas arqueológicas. Algo debió quedar hasta mediados del siglo pasado, ya que I. Fernández y Sánchez (1896), mencionó en su Historia de Talavera de la Reina, la existencia de un foso que corría entre las diversas torres albarranas y que también tenía una "barbacana murada. Antemural que ha ido apareciendo alrededor del primer recinto talaverano tras el derribo de ciertas construcciones que estaban adosadas a la muralla, sobre todo en el sector más occidental (calle del Charcón).

Un paralelo cercano, aunque todavía en fase de excavación y estudio es el del castillo de Calatrava (Carrión de Calatrava, Ciudad Real), estudiado desde hace varios años por J. Zozaya y M. Retuerce, y cuyos primeros resultados se presentaron al III Congreso de Arqueología Medieval Española, Oviedo, 1989 (Retuerce y Zozaya, 1992, 353-359) y últimamente ampliado en Calatrava la Vieja. Diez años de investigación arqueológica (Retuerce, 1994, 213-241). Sabemos que en esa fortaleza se ha documentado un complejo hidráulico por medio del cual se inundaba una serie de fosos, dando a esa fortificación un aspecto de isla, siendo por ello este sistema una solución inmejorable para una zona cuya topografía — un llano- no era la más adecuada para la ubicación de una fortaleza. Según los mencionados autores, es probable que esta solución funcionase ya en el siglo IX. Por otro lado, extraña en sumo grado la falta total de mención en las fuentes a este sistema hidráulico, así como que, con la capacidad de agua almacenada en el interior de ciertas torres se pudiese mantener un nivel de agua aceptable para que el foso tuviese una utilidad militar efectiva.

A diferencia de los conocidos ejemplos de Susa y Almonastir en Ifrīqiya, estudiados ya por varios autores (Lézine, 1956a y 1956b; Golvin, 1969; Marín, 1989 y Martínez Salvador, 1994), donde sí encontramos un esquema de distribución del interior que nos habla de una población allí acuartelada o concentrada, en el caso talaverano no existe 
un edificio especialmente diseñado o planteado como lugar donde habitasen luchadores de la fe. El único edificio que podría alojar a ese contingente militar sería la propia alcazaba. Sin embargo, pensamos que la alcazaba - por lo que las fuentes árabes comentan-se levantó para residencia del gobernador de la ciudad y su ejército. Asimismo, las pocas noticias que tenemos de la alcazaba talaverana y las estructuras hasta ahora reconocidas, nos indican que su distribución interior muy poco tenía que ver con la de los rubut tunecinos. Este esquema tampoco se recoge en otra serie de lugares denominados como ribītt por diversas fuentes e investigadores como el de Yabal al-Ajdar (Allain, 1954, 155-189) o el ribāt de Tît (Basset-Terrasse, 1932, 337-376 y fig.130; Martínez Salvador, 1994, 284-286 y Martínez Lillo, 1995, 153-156).

Al contrario de lo que ocurrió en Ifrīqiya y el Magrib, donde con el paso del tiempo y el progresivo alejamiento de las fronteras, se fue perdiendo el primitivo caracter militar de estos puntos fortificados, Talabīra debió mantener durante gran parte de su historia un eminente carácter militar. Ese carácter militar lo reconocemos en su uso: como base de operaciones en las campanas contra el norte, como punto clave en la defensa del flanco occidental del tagral-awsat, y como almenara desde la que, junto a otros puntos fortificados de la frontera, vigilaba los movimientos de la siempre rebelde ciudad de Toledo, tal y como ya han comentado otros autores (Manzano, 1990, 117 y Souto, 1993, 29).

Con este carácter militar "profesional", no queremos eliminar ni minimizar la constante aportación de elementos ajenos a la esfera castrense. Entre estos elementos ajenos se incluirían los ya mencionados ascetas, hombres piadosos, muŷāhidines, etc.

Es interesante resaltar, ya que no es el motivo de este trabajo, ciertas propuestas últimamente indicadas acerca de la espiritualidad militarista del Islam, la institución islámica del ribat, así como su plasmación en el ŷihād (Epalza, 1993a y 1993b, y Scales, 1993,).

Un aspecto que consideramos interesante saber es la fecha en que debió comenzar la llegada de estos combatientes de la fe. Ya hemos mencionado en páginas anteriores que el carácter fronterizo y militar de Talavera fue constante desde su fundación, con momentos de mayor actividad en época de Muhammad I, destacamentos de caballería en Calatrava y Talavera —año 855/856 241 H.- (Al-Himyari, 1938, 196 y Souto, 1993, 28-29), política de construcción-reconstrucción de fortalezas: Saktān, abandonada en el verano del 915/303 H. por los beréberes baranis de Kutāma (Ibn Hayyān, 1981, 101-102) y Madrid (Ibn Hayyān, 1961, 132 y Zozaya, 1990, 198), y de `Abd al-Rahmān III, noticia de la construcción de la alcazaba de Talavera (al-Rāzī, 1953, 82 y Martínez Lillo, 1990, I, 5), y del al-Hizām de Toledo (Ibn Hayyān, 1981, 240). Por ello es bastante probable que la llegada de estas gentes, ya sea en grupos o de modo individual, coincidiese con los momentos de mayor actividad defensiva en la frontera debido a una clara iniciativa oficial por parte de los omeyas cordobeses.

Precedentes de esta iniciativa oficial al respecto lo tenemos claramente en los casos tunecinos, tal y como nos lo comenta al-Nuwairi en su Nibayat 'Arab para el caso de Sūsa, levantado por el emir aglabí Ziyādat Allah (Ibn Jaldūn, 1978, 412). También es in- 
teresante apuntar que para el caso de al-Andalus y el Magrib (Tarifa, Ceuta, Tánger y Melilla) la amenaza normanda, ya desde época del emir omeya `Abd al-Rahmān II, fuese una razón importante para desarrollar una política de construcción de los rubūt/ribatat (Epalza, 1993a, 66) y almenaras costeras (Terrasse, 1954, 11; Bunes y Martínez Lillo, 1993, 103-105; Lirola, 1993, 347-349 y Azuar, 1995, 67).

Del mismo modo tampoco tenemos información acerca del lugar donde habitaban estas personas. No conocemos noticias que nos pueden indicar si, en el caso de ser pocos y conocidos ascetas, éstos pudiesen compartir alojamiento en dependencias de la alcazaba, o si por el contrario, vivían con los diversos destacamentos militares destinados en esa plaza, o en viviendas de particulares. Sí hay referencias acerca de las personas o gentes que habitaban esas fortalezas, que en los primeros tiempos eran guerreros (militares) y, posteriormente gentes piadosas (Golvin, 1969, 97 y Epalza, 1993b, 14-15). En algunos lugares, como fue el caso de Qairawān, los habitantes y gentes que fundan la ciudad son llamados ya murābitūn (Golvin, 1969, 97). Ibn Marzūq en su Musnad, nos comenta que las gentes que habitaban las torres vigía y mahris del litoral norte del Magrib había quien recibía una soldada, por lo que se trataría también de soldados profesionales (Ibn Marzūq, 1925, 31 y 61 y 1977, 330). Sin embargo, también sabemos que en época del soberano meriní Abū-l-Hasan, estas fortalezas eran ocupadas por "mercenarios" - por lo tanto no voluntarios - no eran consideradas como ribāt-s, siendo más bien torres de vigía, tal y como ya lo mencionó F. Meier (1981, 83 y ).

M. Marín en su ya mencionado trabajo (1989), refiere al hablar del modo de vida de los muräbitūin, que era frecuente que cultivasen sus propias tierras en los alrededores del ribāt (1989, 203). R.H. Idris comenta también la existencia de tierras de labor (ard al-sabil) junto a los rubüt, para que éstas fuesen explotadas en caso de necesidad por los habitantes de la fortaleza, indicando que tendrían que estar necesariamente en el interior de la fortaleza (1962, 690 y Martínez Salvador, 1994, 235 y 241). Esta cuestión no se circunscribió solamente a Ifriqiya o el resto del norte de Africa, sino que también contamos con noticias que nos hablan del mismo hecho para ciertos puntos del Jurasán. Ibn Hawqal nos dice al hablar de un Ribāt Muhammad, que estaba ocupado por una treíntena de hombres que obtenían su sustento de unos campos de labor y unas fuentes de agua (1964, 398).

Lo que por el momento no parece probable, según las estructuras existentes y la documentación gráfica consultada al respecto, es que en el recinto fortificado de Talabīra existiese un lugar específicamente destinado a ese propósito, tal y como sí ocurría en el caso de los referidos ejemplos de Ifrīqiya donde cada miembro de la comunidad que allí vivía tenía su propia celda. Marçais apunta, que el doble carácter - militar y religioso- de la vida de los muräbitūin queda expresado en la arquitectura de los primeros ribāt-s, ya que la planta de Sūsa nos translada a los tiempos en que esta "institución" tenía un caracter netamente guerrero $(1936,1231)$.

Por otro lado, es bastante clara la semejanza en cuanto a los esquemas de las plantas y distribución interna entre estos primeros ejemplos islámicos y los anteriores fuertes bi- 
zantinos que jalonaban gran parte del norte de África magrebí. Ya algún autor ha propuesto este posible precedente y paralelo, mencionando también que los constructores de Sūsa y Monastir serían de origen ifriquí y tendrían en sus mentes más bien modelos bizantinos de esa zona, que los lejanos ejemplos del Oriente Próximo (Marçais, 1954, 133).

Entre los diversos ejemplos existentes en Ifrīqiya como precedentes del modelo tunecino podemos destacar los de Qasr Belezma (Pringle, 1981, II, 563), Limisa (Pringle, 1981, II, 565, fig.16), Gastal (Marçais, 1954, 133 y Pringle, 1981, II, 592, fig. 38a), Tamallulla (Pringle, 1981, II, 594, fig.39) y Tubunae (Pringle, 1981, II, 594). En algun caso, como el de Borŷ Younga (Túnez) — por algunos autores llamado qasr ar-Rümm (Poinssot, 1936-1937, 293) — , el ribāt aglabí se levantó sobre los anteriores restos de la fortaleza bizantina (Major y Martínez Salvador, 1994, II, 367-371 y Martínez Salvador, 1994, 87-95).

Asimismo, precedentes bizantinos, como el caso de Ammaedara (Baratte y Duval, 1974) influyeron de manera considerable en ciertos casos andalusíes, como el de las alcazabas de Mérida y Trujillo (Terrasse, 1954, 14; Hernández, 1940, 200-201 y Valdés, 1995, 270).

Como conclusión de este aspecto aquí presentado decir, para el caso concreto de la Talabīra musulmana por el momento no se puede hablar de la existencia de un edificio en concreto donde habitasen esos luchadores de la fe, pero sí que fuese uno de los lugares donde se fuese "a hacer ribat", así como a otros lugares situados en los alrededores, como las fortalezas de Espejel (Valdelacasa de Tajo, Cáceres), San Vicente (Hinojosa de San Vicente, Toledo), o bien las propias atalayas. Del mismo modo, tampoco se puede buscar un esquema constructivo que responda genéricamente al concepto o misión del ribāt, sí pudiéndose, tal vez, ver otro más bien de ámbito geográfico cláramente asociado al esfuerzo virtuoso en el camino de Dios" (Epalza, 1993a, 75).

Otro aspecto que nos interesa apuntar en este trabajo, es la disposición que tiene alguno de sus elementos existentes en la ciudad, disposición consistente en la proximidad del puente y la puerta de la ciudad con la alcazaba, evidenciando claramente un interés por controlar a toda costa uno de los accesos de la madinna (Hernández, 1940, II). La disposición de esos elementos no es en modo alguno novedosa ni innovadora en al-Andalus, encontrando similares esquemas en otros puntos también fronterizos como los de Toledo, Madrid, Guadalajara y Mérida, estando algo más alejado los de Tudela y Córdoba, entre otros.

Ya en el siglo IX, el emir cordobés `Abd al-Rahmān II mandó levantar en Mérida, tras las sucesivas sublevaciones de la población indígena, una fortaleza para residencia del gobernador nombrado por Córdoba y para la tropa allí destinada $(220$ H./835) (LèviProvençal, 1931, I, 50-53 y II lam.XI,c).

Algo antes (año $161 \mathrm{H} . / 806$ ), siguiendo el comentario de algunas fuentes, el también emir omeya al-Hakam I envía a la zona de Toledo al qā'id muladí `Amrus ibn Yūsuf al-Muwallad, con el fin de apaciguar la ciudad y levantar allí una fortaleza, llamada en 
época de califa `Abd al-Rahmān III, al-Hizām. El emir cordobés le envía para que, desde Talbīra sofoque el levantamiento comandado por el rebelde `Ubayd Allāh b. Humayd. Mediante la donación de riquezas conseguirá finalmente la cabeza del rebelde y el enfrentamiento armado entre los beréberes de Talabīra y Toledo (Ibn Id̄ārī, 1904, 111-112).

Por los textos que nos han llegado sabemos que el motivo de la construcción del al-Hizam fue dar una residencia segura al gobernador y al personal, civil y militar, que le acompañaba. Con este reducto fortificado conseguía separar su guarnición del resto de la población toledana (Ibn al Atīr, 1898, 168 y Delgado, 1987, 196 y 243). Siguiendo la propuesta de C. Delgado Valero, el llamado portillo de los Doce Cantos, sería un postigo de la menciona fortaleza omeya $(1987,227)$. Ibn Idārī, por el contrario, nos da la fecha del 181 H./797 para el momento de esa construcción, mencionando que `Amrus levantó un qașr de sólida construcción junto a la puerta del puente ( $b a \bar{b}$ al-y $\hat{y}$ isr) (1904, II, 112). Con esta obra de ingeniería militar se perseguía el mismo fin que el ejemplo visto para Mérida, ya que, desde esta fortaleza - ya fuese de tapial, mampostería o sillería-, se controlaría el paso por el puente y, a su vez, uno de los accesos o salidas de la ciudad.

Hacia el año 221 H.(835), tras pasar nuevamente la ciudad de Toledo a manos cordobesas el emir 'Abd al-Rahmān II ordena a su hermano Al-Walid b. al-Hakam la reconstrucción del arruinado qasr levantado en época de su padre el emir al-Hakam I (Ibn Idari, 1904, II, 112 y Porres, 1985, 29), siendo muy probable que este recinto fuese el mismo que posteriormente restauró el califa `Abd al-Rahmān III.

Un esquema similar al visto ya para Toledo y que posteriormente también se empleó en Mérida, lo encontramos en el sector de la alcazaba de Talavera de la Reina (Talabīra). En este ejemplo vemos de nuevo el caso de un edificio de cronología y obra islámicas en el que se han utilizado gran cantidad de sillares procedentes de otros anteriores romanos. Asimismo, por el resultado de las excavaciones realizadas en la zona oriental de la alcazaba la disposición de sus muros, al menos el oriental, correspondería al momento de ocupación islámico. En concreto esto queda claramente demostrado en la zona del acceso a la alcazaba, ya que una de sus torres rompe los niveles de enterramiento tardorromano s.III-IV. Desde esta alcazaba se controla con gran facilidad el acceso o salida de la puerta meridional de la ciudad, así como el paso del presumible puente existente ya desde época islámica (Moraleda y Pacheco, 1992, 361-363 y Malalana, 1990, 201-202).

La fecha concreta en que se debió levantar la alcazaba y parte de las murallas, no viene recogida en las fuentes árabes hasta el año $325 \mathrm{H} . / 936-937$, en que el califa `Abd al-Raḥmān III ordena la (re)construcción de parte del recinto amurallado talaverano y en concreto una alcazaba para residencia del gobernador y su tropa (Rāzī, 1953, 82). Sin embargo, sí contamos con noticias del envío de tropas en épocas anteriores. De un lado sabemos la llegada de `Amrūs en calidad de gobernador en el año 181 H./797 (Ibn Idārī, 1091-1904, 102 y 66), probablemente antes de comenzar cualquier acción ofensiva contra Toledo debió reforzar convenientemente las murallas de la ciudad. Por otro, conocemos el envío de tropas y las obras realizadas por voluntad del emir Muhammad b. `Abd 
al-Rahmān a mediados del siglo Ix (año 241 H./855-856) (Lèvi-Provençal, 1938, 196; Molina, 1983, 40 y 55 y Souto, 1993, 29).

Muy pocos restos quedan de la fortaleza islámica de Tudela. Por los pocos trabajos realizados sobre la misma (Souto y Viguera, 1991, 95-127), observamos que el esquema ya propuesto se repite, aunque en este caso hay cierta distancia entre el puente y la alcazaba, en parte debido a las diferentes cotas de altura de cada uno de los elementos (Pavón, 1978, 5-6 y 1986, 29-41). Sin embargo, pensamos que en este caso esta diferencia orográfica facilitaría ese control.

Por otro lado, sabemos que este `Amrūs fue un muladí oriundo de Huesca, que llegó a ser hombre de confianza de los emires Hišām I y al-Hakam I (Viguera, 1995, 4950 ), aunque luego tendría serios problemas con el sucesor del segundo de ellos, ‘Abd al-Rahmān II. Según Oliver Asín, este mawlà aparece como gulām al servicio de los hijos de un poderoso personaje de la zona catalano-aragonesa llamado Sulaymān b. Yaqzān al-Kalbi. Hacia el año 781 pasa cierto tiempo viajando con frecuencia entre las ciudades de Aquisgrán, Barcelona y Gerona, ya que al parecer visitaba a su señor, 'Ayšūn b. Sulayman b. Yaqzan, prisionero de Carlomagno en Aquisgrán (Granja, 1966, 22-23 y Oliver, 1971, 499). Posteriormente, y como agradecimiento a sus servicios prestados en su liberación, ‘Ayšūn le nombra wālì de Barcelona y Gerona (Granja, 1966, 23). A finales del siglo VIII (año 791), con el fin de ganarse la confianza del emir Hisām I, da muerte a su señor, por aquel entonces el hermano de `Ayšūn — Matrūh-y le hace llegar su cabeza a Córdoba (Oliver, 1971, 499).

En el año 181 H. (797), el nuevo emir omeya al-Hakam I le envía a la frontera central (al-tagr al-ausat) para que sofocase la rebelión surgida en Toledo, llegando para ello a Talabira en calidad de gobernador (Ibn Idārī, 1904, 111-112). En fecha similar y tras eliminar al cabecilla de la rebelión, levantará la comentada fortaleza en Toledo ( $\mathrm{Al}$ Hizām), que según Lèvi-Provençal se hizo con muros de tapia $(1950,135)$. Posteriormente marcha, por encargo del emir, contra Zaragoza para sofocar la rebelión del también muladí Bahlūl b. Marzūq, conocido como Abū-l-Haŷ ŷây. Asimismo, levantará en el mismo año (181 H./797) las defensas de Tudela (tal vez alcazaba y murallas), entre las que se incluiría la puerta de la ciudad que daba al puente. A partir de esa fecha pasará a vivir entre las localidades de Tudela y Zaragoza en calidad de gobernador de las mismas ayudado por su hijo Yūsuf (al-Rāzī, 1975, 50-51 y 297). Algo más tarde, año 193 H (809), participa con el emir `Abd al-Rahmān II en la campaña realizada junto a las murallas de Tortosa luchando contra las tropas de Ludovico Pio. Tras serias disputas con el emir, será expulsado de Zaragoza y marchará a Huesca (Oliver, 1971, 503 y Lèvi-Provençal, 1950, 118).

Como recapitulación de lo indicado hasta ahora de este personaje, tenemos a un militar de larga experiencia, al que hay que suponer también con dilatado y amplio conocimiento de lo que fueron los fortines y ciudades amuralladas tardorromanas de la zona. Entre ellas no podemos olvidar, las de Zaragoza (Caesar-Augusta), Huesca (Osca), Toledo (Toletum), Talavera de la Reina (Caesarobriga), Talavera la Vieja (Augustobriga), etc. 
$\mathrm{Al}$ analizar y revisar - aunque no de una manera muy profunda ya que no es objeto principal de este trabajo- las plantas de diversas ciudades amuralladas de época romana de la Península u otras zonas del limes, observamos el lógico y estratégico interés por controlar elementos urbanos como son el castrum, la puerta de la ciudad y el acceso o salida del puente, estando los tres bastante interrelacionados en espacio y función. Este control del recinto fortificado de la ciudad sobre el puente y la puerta dependerá, tanto en época romana como medieval, de los condicionantes topográficos de la zona. Ese control en zonas abruptas o con considerables desniveles no tendrá que ser muy próximo, siendo más cercano en las zonas menos abruptas.

$\mathrm{Al}$ intentar localizar los puntos fuertes de estas ciudades romanas (Córdoba, Toledo, Mérida, Zaragoza) contamos con el inconveniente de su lógica y gradual desaparición o transformación debido al inexorable paso del tiempo (Bendala y Álvarez, 1995, 180). Ya algunos autores al tratar el tema de ciertas poblaciones de origen romano, comentan que el trazado de la ciudad romana, al menos en los casos de los antiguos recintos de Niebla, Écija y Mérida, "... dio al puente como avanzadilla de romanización" (Jiménez, 1977, 226).

En Toledo, como ocurrió en otras ciudades, los restos de urbanismo romano se mezclaron con los posteriores visigodos e islámicos. Sabemos de la existencia de un hábitat fortificado en la zona alta de la ciudad, tal vez viniendo a coincidir en su ubicación con el lugar donde posteriormente se levantó la alcazaba islámica (al-Hizām) (Delgado, 1987, 196). Hoy por hoy, seguimos, desconociendo la importancia del Toledo romano en cuanto a sus restos arquitectónicos se refiere. Si conocemos los restos de la llamada "Cueva de Hércules", al parecer parte del castellum acuae del Toledo romano. También, es un hecho claro que gran parte de las murallas musulmanas de esta ciudad - y de otras peninsulares- se hicieron empleando los anteriores sillares romanos, dándoles una nueva disposición en los paramentos. No debemos olvidar al respecto, los ejemplos de Coria, Talavera de la Reina, Carmona, Mérida, etc. Asimismo, la mano de Roma no se puede negar en el conocido puente de Alcántara, obra en otros momentos concebida como romana o islámica.

Por el comentario de algunos autores es probable que el esquema visto para ciudades como Toledo, Córdoba o Mérida se repita también en otras como Coria, Mérida y Zamora, entre otras. En la Coria romana, y una vez amurallada ésta, el acceso meridional se hacía a través del llamado postigo del Río, vano situado en la muralla en frente del puente que debió existir para el tránsito de la población de una orilla a la otra del Alagón (Díaz, 1956, 279). Por otro lado, apuntar que el actual puente sobre el Alagón —arquitectónicamente hablando- poco tendría que ver con las murallas romanas de la ciudad, ya que éste se data entre los siglos XIV-XV.

En los casos de Mérida y Zamora la búsqueda de estos elementos clásicos es todavía más compleja. En el caso extremeño contamos claramente con los restos del puente romano pero, la antigua ubicación de la fortaleza y puerta romanas fue alterada o suplantada por otra posterior islámica. Por lo tanto, no parece aventurado pensar que de 
alguna manera los arquitectos musulmanes siguieron el anterior esquema romano. Asimismo, no debemos olvidar la importancia de Mérida como capital en época visigoda y cómo resistió su alcazaba los ataques de las huestes islámicas. El autor del Ajbar machmua' nos comenta cómo los musulmanes se vieron obligados a construir máquinas de guerra con las que acercarse a los muros de esta ciudad, y por medio de picos y barras arrancar los sillares (Lafuente, 1867, 29 y 17)). Este es además uno de los pocos textos donde se menciona el empleo de argamasa (al-lāššah māššab) por parte de los visigodos o hispano-romanos en la antigua fortaleza de Mérida.

Por otro lado, es muy probable que el esquema de la referida fortaleza atacada por Tāriq, fuese un modelo a seguir y precedente utilizado por los arquitectos emirales para levantar la alcazaba que mandó edificar `Abd al-Rahmān II, estando en la línea de las fortalezas bizantinas del occidente musulmán como Timgad, Tobna, y Setif, entre otras (Terrasse, 1967, p. 129).

Tal vez la dilatada experiencia adquirida por este muladí en sus constantes visitas a Barcelona, Gerona, Zaragoza, Huesca y demás ciudades de al-Andalus — de claro sustrato urbano romano- le hiciesen reflexionar a la hora de plantearse la construcción de las fortalezas por él levantadas. Los ejemplos de Toledo, Tudela y tal vez Talavera de la Reina podrían ser prueba de ello. Asimismo, se podría presentar similar precedente para la fortaleza levantada por el emir `Abd al-Raḥmān II en Mérida el año 220 H. (835).

\section{BIBLIOGRAFÍA}

Allain, Ch., 1954: "Reconnaissances archéologiques dans le massif des Rehamna et la Bahira. In, Hespéris, t.XLI, pp.155-189.

AZUAR RUIZ, R., 1995: Atalayas, almenaras y rábitas, Al-Andalus y el Mediterráneo, M. ${ }^{2}$ J. Viguera Molins (coor.), Madrid-Barcelona, pp. 67-76.

Baratte, F., y Duval, N., 1974: Les ruines d'Ammaedara, Haïdra, Túnez.

Basset, H., y Terrasse, H., 1932: Sanctuaires et forteresses almohades, París, pp.337-376.

Bendala Galán, M., y Álvarez Martínez, J. M., 1995: -Semblanza de Augusta Emerita", Extremadura Arqueológica IV. Arqueología en Extremadura: 10 años de descubrimientos, pp. 179-190.

BosCH VILÁ, J., 1956: Los almorávides, Tetuán.

Bunes IbarRA, M. A., y Martínez LILlo, S., 1993: ‘La navegación mediterránea en época medieval", II. ${ }^{\circ}$ Curso de Arqueología Subacuática, Universidad Autónoma de Madrid, diciembre de 1992, Madrid, pp. 83-119.

Delgado Valero, C., 1987: Toledo islámico: ciudad, arte e historia, Toledo. 
Díaz Martos, A., 1956: "Las murallas de Coria", Revista de Estudios Extremeños, n. ${ }^{\circ}$ 1-4, pp. 263-295.

EpalzA, M. de, 1985: "Un 'modelo operativo` de urbanismo musulmán”, Sharq Al-Andalus. Estudios Árabes, Alicante, n. ${ }^{\circ}$ 2, pp. 137-149.

- "Espacios y sus funciones en la ciudad árabe", La ciudad islámica, Simposio Internacional sobre la Ciudad Islámica, Zaragoza, 1-4 de diciembre de 1988, Zaragoza, pp. 9-30.

- 1993a: "La rápita hispánica: Historia Institucional", La Ràpita Islàmica: Història Institucional $i$ altres Estudis Regionals. I Congrés de les Ràpites de l'Estat Espanyol (Sant Carles de la Ràpita, 7-10 setembre 1989), Sant Carles de la Ràpita, pp. 62-107.

- 1993b: "La espiritualidad militarista del Islam. El ribat, los ribates, las rábitas y los almonastires de al-Andalus", Medievalismo, 3, n. ${ }^{\circ}$, pp. 5-18.

FERNÁNDEZ y SÁNCHEZ, I., 1896: Historia de la ciudad de Talavera de la Reina, sus claros varones y monumentos, Talavera de la Reina, edición facsímil de 1983.

FrANCO SÁnCHEZ, F., 1988: -El espacio del agua en la ciudad de Orihuela en época islámica", Agua y poblamiento musulmán. Aigua i poblament musulmà (Simposium de Benissa, abril 1987), Benissa, pp. 33-53.

- 1991: "Estudio comparativo del urbanismo islámico de seis poblaciones de la vía Augusta Sagunto / Xativa / Orihuela y Ontinyent / Bocairent / Beneixama", La ciudad islámica, Simposio Internacional sobre la Ciudad Islámica, Zaragoza, 1-4 de diciembre de 1988, Zaragoza, pp. 353-375.

Golvin, L., 1969: "Note sur le mot ribat (terme d'architecture) et son interprétation en occident musulman", Revue de l'occident musulman et de la Médíterranée, n. ${ }^{\circ} 6$, pp. 95-101.

GONZÁl.EZ GONZÁl.EZ, J., 1975: La repoblación de Castilla La Nueva. Madrid, 1975, pp. 57-58.

GRANJA, F. de la, 1966, La Marca Superior en la obra de al-'Udri, Zaragoza.

Hernández Jiménez, F., 1940: The Alcazaba of Mérida. Early Muslim Architecture, t.II, Oxford, pp. 197-205.

Al-Himyārī, 1938: La Péninsule Ibérique au Moyen-Age d'apres le Kitāb ar-Rawd alMi tar fï Jabar al-Aqtār, edic. y trad. E. Lèvi-Provençal, Leiden.

HUiCi MiRANDA, A., 1959: “Alī b. Ŷūsuf y sus empresas en al-Andalus", Tamuda, VII, pp. $77-122$.

- 1961: "Un fragmento inédito de Ibn 'Idārī sobre los almohades" Hespéris-Tamuda, vol.I, pp. 43-111.

- 1963: Ibn 'Idari: Al-Bầān al-Mugrib. Nuevos fragmentos almorávides y almohades, Textos Medievales, 8, Valencia. 
IBN AL-AT̄īr, 1898: Annales du Maghreb et de l'Espagne, trad. E. Fagnan, Argel.

IBN Ḥִ̂YĀN, 1961: Al-Muqtabas II, ed. M. Makki, El Cairo.

- 1981: Crónica del califa ‘Abdarraḅmān III an-Nâsir entre los años 912 y 942 (al-Muqtabis $V$ ), trad. M. ${ }^{a} \mathrm{~J}$. Viguera y $\dot{\mathrm{F}}$. Corriente, Zaragoza.

IBN HAWQAL, 1964: Configuration de la Terre (kitāb Sūrat al-ard, trad. J.H. Kramers y G.Wiet, París.

IBN ID̄ĀRĪ, 1901-1904: Al-Bayano'l-Mogrib, trad, y edic. E. Fagnan, Argel.

- 1904: Histoire de l'Afrique et de l'Espagne intitulée Al-Bayân al-Mugrib, trad. E. Fagnan, t.II, Argel.

- 1951: Al-Hulal al-Mawsiyya. Cronica árabe de las dinastías almorávide, almohade y benimerin, trad. A. Huici Miranda, Tetuán.

IBN JALDŪN, 1978: Histoire des berbères et des dynasties musulmanes de l'Afrique septentrionale, trad. Slane, $3{ }^{a}$ ed., París.

IBN MARZūQ, 1925: "Le Musnad", ed. y trad., E. Lévi-Provençal, Hespéris, t.V, pp.1-82.

- 1977: El Musnad: hechos memorables de Abū l-Hasan sultän de los benimerines, estudio, trad. y anotación M. ${ }^{a} \mathrm{~J}$. Viguera Molins, Madrid.

IDRIS, R. H., 1962: La berbérie orientale sous les zirides. X-XII siècles, París.

JiMÉNEZ, A., 1977: ‘Arquitectura romana de la Bética. I Introducción al estudio de las fortificaciones", Actas del symposium de arqueología romana. Segovia y la arqueologia romana, Barcelona, pp.223-238.

JiMÉNEZ DE GREGORIO, F., 1983: Los pueblos de la provincia de Toledo hasta finalizar el siglo XVIII, t.IV, Toledo.

JiMÉNEZ DE RADA, R., 1968: De Rebus Hispaniae, reimpresión facsímil de la edición de 1793, Valencia.

LAFUENTE y ALCÁNTARA, E., 1867: Ajbar machmua', trad. E. Lafuente y Alcántara, Madrid.

LÈVI-ProvenÇAL, E., 1931: Inscriptions arabes d'Espagne, Leyden-Paris, t.I, pp.50-53, t.II, lám.XI,c.

- 1950: Historia de España, dirigida por R. Menéndez Pidal, t.IV, Madrid.

LÈZINE, A., 1956a: Le ribat de Sousse, suivi de notes sur le ribat de Monastir, Túnez, 1956.

- 1956b: "Deux ribât du Sahel Tunisien", Les Cahiers de Tunisie, n. ${ }^{\circ}$ 15, pp. 279-288.

Lirola Delgado, J., 1993: El poder naval de Al-Andalus en la época del Califato Omeya, Granada. 
Major González, M., y Martínez Salvador, C., 1994: "La fortificación de Borj Younga (Túnez)", IV Congreso de Arqueología Medieval Española, sociedades en transición», Alicante, octubre 1993, Alicante, t.II, pp. 367-371.

Malalana Ureña, A., 1990: "Puentes-fortaleza en el Tajo: el tramo Zorita de los Canes (Guadalajara) Castros (Cáceres)", Boletín de Arqueología Medieval Española, n. ${ }^{\circ} 4$, pp. 195-222.

MANZANO MORENO, E., 1989: La organización fronteriza en al-Andalus durante la época omeya: aspectos militares y sociales (756-976/138-366 H.). Madrid, Universidad Complutense.

- 1990: "Madrid, en la frontera omeya de Toledo" Madrid del siglo IX al XI, Madrid, 1990, pp.115-129.

MarÇAIS, G., 1936: "Ribat", Encyclopédie de l'Islam, III, 1. ${ }^{a}$ ed., p. 1231.

- 1954: L'architecture musulmane d'Occident, París.

MARín Niño, M., 1989: "La vida en los ribāt de Ifrīqiya", La rábita califal de las Dunas de Guardamar (Alicante), Alicante.

MARTÍNEZ LILLO, S., 1990: La arquitectura militar islámica en Talavera de la Reina (Toledo). El primer recinto amurallado, Tesis Doctoral , Madrid, U.A.M.

- 1995, La continuidad de la arquitectura beréber en el Magreb. Ciertos ejemplos en lo militar y lo religioso. La arquitectura del Islam occidental, R. López Guzman (coor.), Madrid, pp. 147-163.

MARTínez SALVADOR, C., 1994: El ribāt en el Mediterráneo occidental: Ifrīqiya y al-Andalus. Dos ejemplos de religiosidad (siglos IX-XI d.C.), Tesis Doctoral inédita, Universidad Autónoma de Madrid.

MEIER, F., 1981: "Almoraviden und Marabute", Die Welt des Islams, vol.XX, pp.80-163.

MORAleda Olivares, A., y PACHECO JimÉnEZ, C., 1992: "Hallazgo de las antiguas estructuras del posible puente romano de Talavera de la Reina", Actas de las Primeras Jornadas de Arqueología de Talavera de la Reina y sus Tierras, Talavera de la Reina, marzo de 1990, Toledo, pp. 361-370.

Molina, L., 1983: Una descripción anónima de al-Andalus, trad. y edic. L. Molina, Madrid.

Oliver Asín, J., 1971: “Origenes de Tudela", Homenaje a D. José Esteban Uranga, Madrid, pp. $495-515$.

PAvÓN MAldonado, B., 1978: Tudela, ciudad medieval: arte islámico y mudéjar, Madrid.

- B., 1986: "La muralla primitiva árabe de Tudela", Anuario de Estudios Medievales, vol.16, pp.29-41. 
PRINGLE, D., 1981: The Defense of Byzantine Africa from Justinian to the Arab Conquest. An account of military bistory and archaeology of the African provincies in the sixth and seventh centuries B.A.R. International Series, 99, Londres.

POINSSOT, L., 1936-1937: "Séance de la commission de l'Afrique du Nord, 9-3-1937", Bulletin de archéologie du Compté, p.293.

Porres Martín-Cleto, J., 1985: Historia de Tulaytula (711-1085), Toledo, 1985.

AL-RĀZī, A., 1953: :La Description de l'Espagne: Essai de reconstitution de l'original arabe et traduction française edic. y trad. E. Lévi-Provençal, Al-Andalus, t.XVIII, pp. 51-108.

- 1975: Crónica del moro Rasis, trad. D. Catalán y M. ${ }^{a}$ S. de Andrés, Madrid.

RetUerCe Velasco, M., 1994: “Calatrava la Vieja. Diez años de investigación arqueológica", Jornadas de arqueología de Ciudad Real en la Universidad Autónoma de Madrid, pp. 213-241.

RetUerce Velasco y ZozaYa Stabel-Hansen, J., 1992: “Un sistema defensivo hidráulico autosuficiente: Calatrava la Vieja", III Congreso de Arqueología Medieval Española, Oviedo 27 marzo-1 abril de 1989, pp. 353-359.

SCALES, P., 1993: "The ribat: the archaeology of a Muslim religious community, Spain", Boletín de Arqueología Medieval, n. ${ }^{\circ}$, pp. 65-75.

SOUTO LASALA, J.A., 1993: "Obras constructivas en al-Andalus durante el emirato de Muhammad I segun el Bayan al-Mugrib", Arqueologia Medieval, 3, pp. 27-31.

Souto Lasala, J.A., y Viguera Molins, M. ${ }^{a}$ J., 1991: "Aportaciones al estudio de una madìna andalusí de frontera: Tudela", La Marche Supérieure d'al-Andalus et l'Occident chrétien, P. Sénac (ed.), Madrid, pp. 95-127.

Terrasse, H., 1954: "Les forteresses de l'Espagne musulmane", Cátedra de la Fundación del Excmo. Sr. Conde de Cartagena, Madrid.

- 1967: :Les influences orientales sur l'art musulman d'Espagne", Studia Islamica, t.XXVII, pp.123-148.

- 1970: "Talavera hispano-musulmane (notes historico-archéologiques)", Mélanges de la Casa de Velazquez, t.VI, pp.79-112.

VALDÉS FERNÁNDEZ, F., 1995: "Arqueología islámica de Extremadura: los primeros cuatrocientos años", Extremadura Arqueológica IV, Madrid, pp. 265-296.

VAllvÉ Bermejo, J., 1975: “Una descripción de España de Ibn Gālib”, Anuario de Filología, pp.369-384.

Viguera Molíns, M. ${ }^{2}$ J., 1995: El Islam en Aragón, Zaragoza.

ZOZAYA STABel-HanSEN, J., 1990: "El Islam en la región madrileña", Madrid del siglo IX al $X I$, Madrid. 